\title{
A importância da contabilidade nos processos de gestão das cooperativas de crédito
}

\section{The importance of accounting in credit cooperative management processes}

DOI: $10.46814 /$ lajdv2n3-002

Recebimento dos originais: 10/03/2020

Aceitação para publicação: 10/03/2020

\section{Jaciara Xavier Pereira Ribeiro}

Doutoranda em Ciências da Educação pela Instituição Brasil de Educação e Pesquisa - IBEP, em parceria com a Universidade Nacional de La Plata e Universidade Del Sol

Instituição: Instituição Brasil de Educação e Pesquisa - IBEP, em parceria com a Universidade Nacional de La Plata e Universidade Del Sol - UNADES/IBEP/BRASIL

Endereço: UNADES - 14 De Mayo 462, Asunción, Paraguai/ IBEP - sede no Calçadão Arthur Bernardes, $n^{\circ}$ 152, Sala 06, Bairro Centro, Viçosa - MG - CEP 36.570- 061

E-mail: jaciaraxp@yahoo.com.br

\section{RESUMO}

A contabilidade é a ciência responsável pelo estudo dos fenômenos ocorridos no patrimônio das empresas, sendo responsável pelo registro, classificação e demonstração dos fatos ocorridos no patrimônio, através da escrituração contábil. O estudo foi realizado em uma Cooperativa de Crédito denominada SICOOB União. Sendo assim, para a definição do problema de pesquisa levou-se em consideração a expectativa de investigar a importância da Contabilidade nos processos de gestão das cooperativas de crédito. A questão problema da pesquisa é: Como a contabilidade contribui nos processos de gestão das cooperativas de crédito? Tendo como objetivo geral: Apresentar as contribuições da contabilidade nos processos de gestão das cooperativas de crédito e objetivos específicos: Descrever conceitos sobre a contabilidade e seus tipos, Sistemas de informações gerenciais e cooperativismo com foco no ramo crédito; Analisar os dados contábeis e discutir os resultados apresentados nos relatórios emitidos pelos Sistemas de Informações gerenciais, indicadores e gráficos utilizadas pelo SICOOB União, mês base setembro de 2018; Comparar a evolução dos números financeiros da cooperativa com base nos 10/2017 e 09/2018; e por fim, avaliar a situação financeira do SICOOB União com base nos números apresentados. Os objetivos foram alcançados, respondendo à questão problema. Como limitação do artigo, a metodologia utilizada para pesquisa foi descritiva, apenas com revisão documental e bibliográfica, neste sentido, sugere-se a realização de novas pesquisas, desta vez de forma quantitativa ou qualitativa na Cooperativas de Crédito pesquisa, de forma a ampliar as conclusões sobre a importância da contabilidade nos processos de gestão das cooperativas de crédito.

Palavras-chave: Contabilidade, Sistemas de Informações Gerenciais, Cooperativismo.

\begin{abstract}
Accounting is the science responsible for studying the phenomena that occurred in the companies' equity, being responsible for the registration, classification and demonstration of the facts that occurred in the equity, through the bookkeeping. The study was carried out in a Credit Cooperative called SICOOB União. Therefore, in order to define the research problem, the expectation of investigating the importance of Accounting in the management processes of credit cooperatives was taken into account. The research question is: How does accounting contribute to the management processes of credit unions? Having as general objective: To present the contributions of accounting in the management processes of credit
\end{abstract}


unions and specific objectives: Describe concepts about accounting and its types, Management information systems and cooperatives with a focus on the credit branch; Analyze the accounting data and discuss the results presented in the reports issued by the Management Information Systems, indicators and graphs used by SICOOB União, base month September 2018; Compare the evolution of the cooperative's financial numbers based on 10/2017 and 09/2018; and finally, assess the financial situation of SICOOB União based on the figures presented. The objectives were achieved, answering the problem question. As a limitation of the article, the methodology used for the research was descriptive, with only documentary and bibliographic revision, in this sense, it is suggested to carry out new research, this time in a quantitative or qualitative way in the Credit Cooperatives research, in order to expand the conclusions on the importance of accounting in the management processes of credit unions.

Keywords: Accounting, Management Information Systems, Cooperativism.

\section{INTRODUÇÃO}

A contabilidade é a ciência responsável pelo estudo dos fenômenos ocorridos no patrimônio das empregas, sendo responsável pelo registro, classificação e demonstração dos fatos ocorridos no patrimônio, através da escrituração contábil, que fornece informações para análise e interpretação dos fatos ocorridos, sendo possível conhecer as variações que ocorreram no patrimônio, tendo das finalidades básicas: uma ligada ao planejamento servindo de base para análise de situações futuras, e a outra ao controle do que aconteceu com a instituição. A contabilidade existe desde o início da civilização humana, no qual o homem observou que era preciso controlar administrar e preservar seus bens e que através deste controle e obter lucros.

O estudo foi realizado na Cooperativa de Crédito de Livre Admissão da União dos Vales do Piranga e Matipó Ltda, sigla SICOOB União que segundo Pinheiro (2008, p.7), são instituições financeiras constituídas sob a forma de sociedade cooperativa, tendo por objetivo a prestação de serviços financeiros aos associados. O Sicoob destaca-se atualmente como o maior e mais estruturado sistema de cooperativas de crédito do Brasil.

Para Leite e Senra (2005, p. 174), as cooperativas de crédito possuem diferenças com relação aos bancos.

Vergara (2005, p.32) aborda que o autor de um estudo o justifica ao atribuir-lhe contribuições de ordem prática ou ao estado da arte na área. Neste sentido o presente trabalho poderá trazer como contribuição prática, o conhecimento sobre a importância da Contabilidade nos processos de gestão das Cooperativas de crédito através de dados fornecidos pelos demonstrativos contáveis, sistemas de informações gerenciais e indicadores, para um efetivo planejamento e controle, bem como eficiência e eficácia na tomada de decisão em relação ao negócio administrado.

Sendo assim, para a definição do problema de pesquisa levou-se em consideração a expectativa de investigar a importância da Contabilidade nos processos de gestão das cooperativas de crédito. $\mathrm{O}$ 
problema é expresso, então, pela questão: Como a contabilidade contribui nos processos de gestão das cooperativas de crédito? Tendo como objetivo geral: Apresentar as contribuições da contabilidade nos processos de gestão das cooperativas de crédito e objetivos específicos: Descrever conceitos sobre a contabilidade e seus tipos, Sistemas de informações gerenciais e cooperativismo com foco no ramo crédito; Analisar os dados contábeis e discutir os resultados apresentados nos relatórios emitidos pelos Sistemas de Informações gerenciais, indicadores e gráficos utilizadas pelo SICOOB União, mês base setembro de 2018; Comparar a evolução dos números financeiros da cooperativa com base nos 10/2017 e 09/2018; e por fim, avaliar a situação financeira do SICOOB União com base nos números apresentados.

Este artigo está estruturado em capítulos, incluindo a introdução, na qual se apresenta o a justificativa do estudo, problema de pesquisa, os objetivos e a estrutura do artigo. Os demais capítulos organizam-se da seguinte maneira: no segundo aborda-se o desenvolvimento sobre conceitos sobre contabilidade e seus tipos, sistemas de informações gerenciais e cooperativismo; no terceiro será apresentado O Estudo em uma cooperativa de Crédito- SICOOB União; metodologia; os sistemas de informações gerenciais e indicadores utilizados no SICOOB União e Análise dos dados contábeis e discussões dos resultados; no quarto formulam-se as conclusões, acrescidas das limitações e sugestões para novos estudos, e por fim são apresentadas as referências.

\section{DESENVOLVIMENTO}

Conforme Sant'Anna (2018): "A Contabilidade é a ciência que, através de seus princípios e conceitos, registra as transações financeiras de forma que permite o controle efetivo do patrimônio de uma entidade".

É o que afirma Franco (1997):

A Contabilidade é a ciência que estuda os fenômenos ocorridos no patrimônio das entidades, mediante o registro, a classificação, a demonstração expositiva, a análise e a interpretação desses fatos, com o fim de oferecer informações e orientação - necessárias à tomada de decisões - sobre a composição do patrimônio, suas variações e o resultado econômico decorrente da gestão da riqueza patrimonial.

Nunes (2018) relata que:

O surgimento da contabilidade pode ser explicado pela necessidade de suprir as limitações da memória humana mediante um processo de classificação e registro que lhe permitisse recordar facilmente as variações sucessivas de determinadas grandezas, para que em qualquer momento pudesse saber a sua dimensão. Progressivamente a contabilidade transforma-se numa fonte de informações na medida em que pode facultar a qualquer momento o conhecimento da situação da empresa e o andamento dos seus negócios. 
Segundo Marques (2004):

Para os administradores, o interesse nos dados contábeis atinge um grau de profundidade e análise, bem como de frequência, muito maior do que para os demais usuários. De fato, são eles os agentes responsáveis pelas tomadas de decisões dentro de cada organização a que pertencem. Note-se que as informações fornecidas pela contabilidade não se limitam, como julgam muitos, ao Balanço Patrimonial e à Demonstração de Resultados. Além desses demonstrativos básicos e finais de um período contábil, a contabilidade fornece aos administradores um fluxo contínuo de informações sobre os mais variados aspectos da gestão financeira e econômica das empresas. O gestor que sabe usar a informação contábil, e que conhece suas limitações, dispõe de um poderoso instrumental de trabalho que lhe permite tomar decisões visando o futuro com maior segurança, bem como conhecendo a situação atual e o grau de acerto e impropriedade de suas decisões anteriores.

Marques (2004) menciona ainda que:

A contabilidade, na qualidade de metodologia especialmente concebida para captar, registrar, acumular, resumir e interpretar os fenômenos que afetam as situações patrimoniais, financeiras e econômicas de qualquer entidade, tem um campo de atuação muito amplo. Sua aplicação se dá em entidades com finalidades lucrativas ou não, que tenham necessidade de exercer atividades econômicas para cumprir com seu objetivo social. A atuação da contabilidade sobre o patrimônio das entidades possibilita respostas às necessidades informacionais dos sócios ou acionistas das organizações, respondendo-lhes perguntas como: qual a taxa de lucratividade proporcionada ao investimento em ações ou quotas da sociedade? Será que a empresa continuará a oferecer, no médio e longo prazo, perspectivas de rentabilidade e segurança para seu investimento? Existe alguma alternativa mais adequada para seus investimentos?

Para Sant'Anna (2018:

A informação contábil é uma ferramenta extremamente importante para o sucesso de qualquer empresa, mas não deve apenas se restringir ao atendimento das determinações legais, pois deve contribuir decisivamente para a tomada de decisão pelos gestores da empresa, bem como por outros usuários interessados nas informações (como acionistas, investidores, empregados etc.).

\section{Conforme Atkinson et al (2000):}

No contexto competitivo atual, os contadores gerenciais estão se tornando parte do time executivo, participado da formulação e da implementação de estratégias. Os contadores gerenciais podem converter o plano estratégico em medidas operacionais e administrativas. Em vez de serem coletores de dados e produtores de relatórios descritivos, podem tornar-se projetistas de importantes sistemas de informações gerenciais para a empresa.

\subsection{TIPOS DE CONTABILIDADE}

Com a definição do termo contabilidade e sua importância, a seguir serão apresentados os tipos de contabilidade existentes, sendo a de custo, pública, tributária, financeira, gerencial e ao final os sistemas de informações gerenciais contábeis.

A contabilidade de custos é definida como "uma técnica ou método para determinar o custo de um projeto, processo ou objeto. Além disso, o IMA sugere que essas informações sejam determinadas por 
meio de uma medida direta, uma ação arbitrária ou alocação sistemática e racional" (ELDENBURG \& WOLCOTT, 2007).

Segundo Carvalho (2010), "contabilidade pública é o ramo da ciência contábil que tem como objetivo aplicar os conceitos, os princípios e as normas contábeis nos atos e fatos de gestões orçamentária, financeira, patrimonial e de compensação, nos órgãos e entidades da administração pública, direta e indireta e ainda fornecer informações tempestivas, compreensíveis e fidedignas à sociedade e aos gestores públicos". Ainda:

De acordo com a resolução do Conselho Federal de Contabilidade - CFC No 1.128 de 21.11.2008 NBC T 16.1/2008:

(...) a contabilidade aplicada ao setor público é o ramo da ciência contábil que aplica, no processo gerador de informações, os princípios fundamentais de contabilidade e as normas contábeis direcionados ao controle patrimonial de entidades do setor público. O objetivo da contabilidade aplicada ao setor público é fornecer aos usuários informações sobre os resultados alcançados e os aspectos de natureza orçamentária, econômica, financeira e física do patrimônio da entidade do setor público e suas mutações, em apoio ao processo de tomada de decisão; a adequada prestação de contas; e o necessário suporte para a instrumentalização do controle social (...).

Para Oliveira et al (2006):

(...)a contabilidade tributária é o ramo da contabilidade responsável pelo gerenciamento dos tributos incidentes nas mais variadas operações realizadas por uma empresa, ou grupo de empresas, adaptando ao dia-a-dia empresarial as obrigações tributárias, de forma a não expor a entidade às possíveis sanções fiscais e legais.

Segundo Eldenburg e Wolcott (2007), a contabilidade financeira "é o processo que trata da preparação e do fornecimento das informações financeiras que os tomadores de decisão externos à empresa - como os acionistas e os credores - utilizam com bastante frequência".

Stair e Reynolds (2011), entendem que a contabilidade financeira "consiste em captar e registrar todas as transações que afetam o estado financeiro de uma empresa e, depois, usar essas transações documentadas para preparar declarações financeiras para tomadores de decisões externos, como investidores, fornecedores, bancos e agências governamentais".

Para Sant'Anna (2018):

A contabilidade financeira, ou geral, por ser uma ciência social, é universal. Obedece aos princípios e às convenções contábeis geralmente aceitos que, em muitos casos, são passíveis de adaptações em função do próprio ambiente interno (mercado e política econômica e financeira), de cada país. A forma e a falta de padronização de apresentação das informações de desempenho pela contabilidade financeira ou geral trazem dificuldades para os gestores (usuários internos) em suas análises e tomadas de decisões. 
Para Crepaldi (2006):

(...) contabilidade gerencial é o ramo da contabilidade que tem por objetivo fornecer instrumentos aos administradores de empresas que os auxiliem em suas funções gerenciais. É voltada para a melhor utilização dos recursos econômicos da empresa, através de um adequado controle dos insumos efetuado por um sistema de informação gerencial.

\subsection{SISTEMAS DE INFORMAÇÕES GERENCIAIS}

Conforme Vico Mañas (2012), "Todo sistema de informações gerenciais é composto por fontes internas e externas à organização. Essas fontes permitem trazer fatos do passado, presente e projetar o futuro ou cenários prováveis". Desse modo, embora as finalidades para as quais se usa a informação contábil possam ser demonstradas de variadas formas, podemos agrupá-las em duas formas básicas: controle e planejamento.

Marques (2004):

Os usuários das demonstrações fornecidas pelo Sistema de Informação Contábil são todas pessoas físicas ou jurídicas que tenham interesse na avaliação da situação e do progresso de determinada entidade, seja uma empresa, uma entidade de finalidades não-lucrativas ou mesmo um patrimônio familiar, e é nessa perspectiva que se aborda a contabilidade e o ambiente, ou seja, de que forma a contabilidade contribui para o ambiente global e de que maneira ele capta os dados externos para processá-los e transformá-los em informações úteis para o processo de tomada de decisões.

Padoveze (2012), diz que" as necessidades dos gestores das empresas, de informações contábeis para o processo de planejamento, execução e controle de suas atividades e para avaliação de desempenho, são supridas pelos diversos instrumentos de contabilidade gerencial por meio do sistema de informação contábil gerencial".

Conforme Marques (2004):

O Sistema de Informação Contábil tem por objetivo a produção de informações destinadas a prover seus usuários com demonstrações contábeis e análises de natureza econômica, financeira, física, de resultados, de desempenho e de produtividade com relação à entidade, objeto de contabilização. Ao se procurar demonstrar os objetivos do Sistema de Informação Contábil, podemos descrevê-los como sendo os de: prover informações monetárias e não monetárias, destinadas às atividades e decisões dos níveis operacional, tático e estratégico da empresa, e também para os usuários externos a ela; constituir-se na peça fundamental do sistema de Informação Gerencial da empresa.

\section{Ainda para Marques (2004):}

A contabilidade, vista como um sistema, dada a sua função no ambiente organizacional, possui a característica de consolidar de forma convergente os demais sistemas de outras áreas da empresa, inclusive os de missões operacionais (compras, contas a pagar, contas a receber, tesouraria, faturamento etc.). Esses são, nesse momento, os subsistemas daquele (sistema de informação contábil), uma vez que ocorre um fluxo de seus dados em direção ao mesmo para transformá-los em informações úteis para o processo decisório. 
Continuando com Marques (2004):

O controle, na literatura, é sempre considerado como uma forma complementar ao planejamento. É, portanto, de grande utilidade reconhecer o controle em seus contornos possíveis para torná-lo um meio eficaz na busca de resultados, independentemente do contexto onde possa ser aplicado, em organizações de pequeno ou grande porte, com ou sem fins lucrativos. Os responsáveis pela administração das organizações (gestores dos negócios) precisam entender e enxergar o controle em toda a sua extensão e potencialidade, como meio de alcançar os objetivos organizacionais. Quando essa visão for assimilada, poderá o processo de controle ser aplicado de forma eficaz, servindo como ferramenta útil ao processo de tomada de decisão.

Conforme Marques (2004), "para tanto, as organizações têm investido em tecnologia e em estudos para conceber métodos eficazes de tratamento das informações extraídas da contabilidade e que estão no ambiente organizacional, interno e externo, buscando, assim, a excelência empresarial".

\subsection{COOPERATIVISMO}

Pelo fato de o estudo ser realizada em uma Cooperativa de Crédito, se faz necessário a definição de alguns termos relacionados ao ambiente cooperativista para melhor entendimento. O cooperativismo é tido como um dos principais instrumentos para a promoção de desenvolvimento econômico e social, pois gera e distribui renda e promove o capital social nas comunidades que o praticam (BIALOSKORSKI NETO, 2002, p.77:97).

A respeito do surgimento do cooperativismo, Correia e Moura (2001, p.5) e Braga (2001) afirmam que a doutrina do cooperativismo teve origem no final do século XVIII e metade do século XIX, na Inglaterra, época da Revolução Industrial, onde havia muitas fábricas repletas de operários carregados de problemas e necessidades, pois, enquanto as fábricas prosperavam, os operários viviam quase na miséria: muitas horas de trabalho, salários muito baixos, desemprego, fome, etc.

Em meio a todos estes problemas alguns operários resolveram reunir-se para procurar uma solução, e sentiram que só através da cooperação poderiam sobreviver à crise. Através da união de 28 tecelões (operários) foi criado, então, um pequeno armazém cooperativo de consumo, a "Sociedade dos Equitativos Pioneiros de Rochdale". Assim foi lançada, em Rochdale, no ano de 1844, a semente do Cooperativismo.

Em um período curto de tempo estes tecelões começaram a se profissionalizar, elaborando estratégias como aquisição de casas para os associados, formação de um capital social para emancipação dos trabalhadores e criação de estabelecimentos industriais e agrícolas para a produção de bens indispensáveis a preços baixos. Enquanto a lógica do capitalismo instituía a competição, o novo sistema estimulava a cooperação (SANTOS, 2002, p. 11). 
Para Rech (2000, p.144-5) o cooperativismo tem características similares no mundo todo, tendo posição a partir das óticas capitalista e socialista; na visão capitalista atenuam-se as características de concentração de capital, e na visão socialista surge como alternativa de uma nova ordem econômica e social.

O cooperativismo está embasado em sete princípios, quais sejam: adesão voluntária e livre, gestão democrática pelos membros, participação econômica dos membros, autonomia e independência, educação, formação e informação, intercooperação, interesse pela comunidade. (STEFANO; ZAMPIER; GRZESZCZESZYN, 2006).

Estes princípios veem se modificando ao longo dos tempos. A Cooperativa trata-se de um segmento representado por organizações de pessoas que se unem, de forma voluntária, para cobrir necessidades econômicas, sociais e culturais comuns, por meio de uma empresa de propriedade coletiva e democraticamente gerida. Baseando-se em valores de ajuda mútua, responsabilidade, democracia, igualdade, eqüidade e solidariedade. Criadas com um propósito inicial de "defender" e proteger o sustento de comunidades das imperfeições do mercado (COOK e PLUNKETT, 2006).

A Organização das Cooperativas Brasileiras (OCB) classifica as cooperativas do Brasil em treze ramos distintos: agropecuário, consumo, crédito, educacional, especial, habitacional, infraestrutura, mineral, produção, saúde, trabalho, transporte e turismo e lazer (OCEMG, 2011, p.8:9).

\section{ESTUDO EM UM COOPERATIVA DE CRÉDITO - SICOOB UNIÃO}

A METODOLOGIA utilizada quanto aos meios de investigação, para a realização deste estudo, tornou-se necessário o desenvolvimento de uma pesquisa descritiva através de técnicas de levantamento documental e de caráter bibliográfica, conceituando termos relacionados aos conceitos gerais sobre Contabilidade, sistemas de informações gerenciais e cooperativismo. Constatando que as ciências contábeis vêm se transformando contribuindo para a gestão do negócio, contribuindo para o planejamento, controle, eficiência e eficácia na tomada de decisão.

O estudo foi realizado na Cooperativa de Crédito de Livre Admissão da União dos Vales do Piranga e Matipó Ltda. SICOOB União, constituiu-se em Assembleia Geral, de 04 de maio de 1.995, com sede e administração na cidade de Raul Soares, Estado de Minas Gerais, com área de ação limitada ao município sede e aos seguintes municípios: Abre Campo, Acaiaca, Amparo do Serra, Araponga, Alvinópolis, Barra Longa, Bom Jesus do Galho, Cajuri, Canaã, Coimbra, Córrego Novo, Diogo de Vasconcelos, Dionísio, Dom Silvério, Guaraciaba, Jequerí, Oratórios, Pedra do Anta, Piedade de Ponte Nova, Piranga, Ponte Nova, Porto Firme, Rio Casca, Rio Doce, Santa Cruz do Escalvado, Santo Antônio do Grama, São Geraldo, São José do Goiabal, São Miguel do Anta, São Pedro dos Ferros, Sem Peixe, Sericita, Teixeiras, Urucânia, Vermelho Novo, Viçosa. 


\subsection{SISTEMAS DE INFORMAÇÕES GERENCIAIS UTILIZADAS NO SICOOB UNIÃO}

A seguir será apresentado o relatório emitido pelos Sistemas de Informações Gerenciais (SIG) utilizadas nas cooperativas de crédito SICOOB, mês base 09/2018, conforme figura 1. O relatório de indicadores apresentado a seguir, conforme figura 2, possibilita ao gestor, a comparação dos números da Cooperativa SICOOB União, em relação aos Consolidados da Central, Tipo e SICOOB em geral, podendo avaliar se está dentro dos padrões desejados.

Figura 1: Relatório SIG 09/2018

\begin{tabular}{|c|c|c|c|c|c|c|}
\hline 3164 - SICOOB UNIÄO & & \multicolumn{2}{|c|}{$\begin{array}{l}\text { Sisbr } 2.0 \text { - Plataforma de Apoio à Decisão } \\
\text { APN - Análise de Produtividade do Negócio } \\
\text { Relatório de Apuração de Resultado }\end{array}$} & \multicolumn{3}{|c|}{$\begin{array}{l}\text { Data Emlssäo : } \\
23 / 41 / 2018 \\
\text { Hora Emlssâo: } \\
08: 22: 47\end{array}$} \\
\hline \multicolumn{2}{|l|}{$\begin{array}{l}\text { Data de Referência: } \quad 09 / 2018 \\
\text { Instituição: } 3164-S I C O O B \text { UNIĀO }\end{array}$} & \multicolumn{2}{|r|}{ Data/Hora Processamento: } & \multicolumn{3}{|c|}{ 11/10/2018 18:25:03 } \\
\hline \multicolumn{3}{|l|}{$\begin{array}{l}\text { Spread Global: } 0,94 \\
\text { ORIGEM DE RECURSOS (A) }\end{array}$} & \multicolumn{4}{|c|}{$\begin{array}{c}\text { Taxa de Custo de Oportunldade: } 0,47 \% \text { (Taxa médlia mensal do CDI) } \\
\text { APLICAÇÃO DE RECURSOS (B) }\end{array}$} \\
\hline Saldo Móla Dläs Carridos (SMC) & Taxa(\%) & Desposa Gerada & 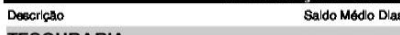 & Coritdos (SMC) & Taxa|\%) & Föcelta Gerada \\
\hline DEPÓSITOS & 0,30 & (536.423) & TESOURARIA & 74.880 .656 & 0,43 & 322.524 \\
\hline Depbsito a Vista & - & - & Caixa & 6.132.082 & - & - \\
\hline Depósito a Prazo & 0,44 & $(536.423)$ & Depósitio Bancários & 0 & . & \\
\hline $\mathrm{CDI}$ & 0,00 & 0 & Centralizaģăo Financeira & 88.462.399 & 0,47 & 321.470 \\
\hline 744.795 & 0,45 & $(3.365)$ & Aplicaçăo Titulo Privado & 223.052 & 0,47 & 1.054 \\
\hline $108.606 .7 \pi$ & 0,44 & $(476.237)$ & Aplicaçăo Titulo Público & 0 & 0,00 & \\
\hline 13.516 .673 & 0,42 & $(56.822)$ & Outros Tesouraria & 63.123 & 0.00 & \\
\hline Centraltzaģāo Financeira & 0,00 & 0 & OPERAÇŌES DE CRÉDITO & 167243.377 & 1,69 & 2.831.397 \\
\hline Outros & 0,00 & 0 & Adiantamento a Depositantes & 314.373 & 13,58 & 42.687 \\
\hline RELAÇס̋ES INTERFINANCEIFAS & 0,00 & 0 & Emprestimos Totals & 92.810 .974 & 1,93 & 1.786 .632 \\
\hline REPASSES E EMPRÉSTIMOS & 0,54 & $(170.115)$ & Empréstimos & 86.878 .401 & 1,69 & 1.467 .547 \\
\hline Bancoob/Outros & 0,54 & (170.115) & Conta Garantida & 3.503 .342 & 4,80 & 168.218 \\
\hline Cooperativa Central & 0,00 & 0 & Cheque Especial & 2.429 .231 & 6,21 & 150.867 \\
\hline Ropasses/Emprostimos & 0,00 & $\mathbf{0}$ & Tftulos Descontados & 12.865 .672 & 1,95 & 250.673 \\
\hline OUTRAS OBRIGAÇÕES & & . & Financiamentos & 22.902 .169 & 1,60 & 366.723 \\
\hline Recursos Transitorios & & - & Operaços Renegociadas & 5.133 .361 & 1,51 & 7.530 \\
\hline Provisão Tributos Federais & & $\cdot$ & Financiamentos Rurais Totais & 40.328 .765 & 0,76 & 307.152 \\
\hline Coobrigą̧̄öss & & - & Financiamentos Agroindustriais & 0 & 0,00 & \\
\hline Outros & & - & Financiamentos Rurais RPL & 12.165 .878 & 1,26 & 153.892 \\
\hline RESULTADOS DE EXER. FUTUROS & - & - & Financlamentos Rurais Direcionados & 28.162 .886 & 0,54 & 153.260 \\
\hline PATRIMOONIO LIQUIDO & . & . & Financiamentos Rurais Fontes Públicas & 0 & 0,00 & \\
\hline Capital Social & & - & Provisāo para Oper.Crédito & (7.141.937) & - & \\
\hline Reservas & & . & OUTROS CRÉDITOS & 2.425 .393 & & \\
\hline Sobras/Pordas Exer Antorior & - & - & Depsisito da PIS/COFINS & 458.944 & - & \\
\hline \multirow[t]{7}{*}{ Sobras/Perdas Exer-Atual } & . & . & Outros & 1.966 .449 & & \\
\hline & & & BENS NÃO DE USO PRÓPRIO & 286.075 & - & \\
\hline & & & PERMANENTE & 14.872 .763 & & \\
\hline & & & Investimentos & 6.680 .928 & . & \\
\hline & & & Imobilizado & 8.191 .835 & . & . \\
\hline & & & Diferido & 0 & . & \\
\hline & & & Intangivel & 0 & & \\
\hline TOTAL & 0,27 & $(706.539)$ & TOTAL & 259.678 .264 & 1,21 & 3.153 .921 \\
\hline$\Leftrightarrow$ MARGEM FINANCEIRA (B) $+($ A) & & & & & & 2.447 .382 \\
\hline (-i+)Provisăo//Reversăo de CL/Garantias Prestadas & & 122.945 & (+) Recuperaçăo de Prejulzo & & & 40.401 \\
\hline$\Leftrightarrow$ RESULTADO DA INTERMEDIAÇĀO FINANCEIRA & & & & & & 2.610 .728 \\
\hline (+) Outras Receltas Operacionals & & 904.956 & () Outras Despesas Operacionals & & & (807.028) \\
\hline (t) Rendas do Servigos & & 877.089 & $(\rightarrow$ Custos de Serviços Bancários & & & (94.906) \\
\hline (+) Cancóes & & 118.262 & $\Leftrightarrow \rightarrow$ Despesas com Cartóes & & & (45.657) \\
\hline (+) Segunos & & 85.665 & $\Leftrightarrow$ Rateio da Central & & & (76.560) \\
\hline$(+)$ SIPAG & & 25.170 & $\leftrightarrow$ - Depreciaçăo/Amortizaçāo & & & (76.391) \\
\hline (+) Tarfas $\mathrm{C} / \mathrm{C}$ & & 371.007 & $\leftrightarrow$ Gontribuiẹăo para Fundos Garantidores & & & $(23.060)$ \\
\hline (+) Rendas Cobrança Bancária & & 119.157 & $\leftrightarrow$ Despesas Tributos Federals & & & (191.301) \\
\hline (+) Consónicio & & 49.214 & $\leftrightarrow$ - Despeses de Juros ao Gapital & & & $(76.470)$ \\
\hline (+) Poupança & & 33.666 & $\leftrightarrow$ Outras & & & (222.682) \\
\hline (+) Sicosob Previ & & & & & & \\
\hline (+) Consignado Bancoob & & 26.591 & & & & \\
\hline (+) Outras Rendas de Servigos & & 48.358 & & & & \\
\hline$(+)$ Outras Rendas & & 27.866 & & & & \\
\hline$\Leftrightarrow$ MARGEM DE CONTRIBUIÇÃOO & & & & & & 2.708 .655 \\
\hline (-) DESPESAS ADMINISTRATINAS & & $(1.538 .825)$ & (-) Processamento de Dados & & & (73.334) \\
\hline (-) Água e Energia & & $(19.763)$ & (-) Promogōos, Rel. Públicas, Pub. \& Publicą̧ōos & & & (9.672) \\
\hline (-) Aluguéis e Arendamentos & & $(60.274)$ & H) Services de terceiros & & & (65.016) \\
\hline$\rightarrow$ Comunicąóes & & $(53.370)$ & (-) Vigilancia e Segurança & & & (98.633) \\
\hline (-) Honorarios de Com. Fiscal, Adm. E Diretoria & & (120.529) & (-) Transportes o Viagens & & & (41.634) \\
\hline$\rightarrow$ Despesa de Pessoal & & (872.674) & $\rightarrow$ Outras Administrativas & & & (76.664) \\
\hline$\leftrightarrow$ - Manutẹăo e Conserva̧̧ăo & & (35.913) & $\leftrightarrow$ Despesas năo Operacionais & & & (53.287) \\
\hline$(\rightarrow)$ Materials & & (11.349) & (+) Recottas não Operacionats & & & 4.869 \\
\hline ( $=$ ) RESULTADO ACUMULADO NO SEMESTRE & ( $\Rightarrow \mathrm{RE}$ & SULTADO ACU & ADO NO EXERCICIO & SULTADO F & & \\
\hline 3.481 .017 & & 7.0 & & 1.121 .227 & & \\
\hline
\end{tabular}

Fonte: SICOOB União 
Figura 2 Relatório de Indicadores

\begin{tabular}{|c|c|c|c|c|}
\hline $\begin{array}{l}\text { SIC4 - SICOOB UNIÃO } \\
\text { S1COO }\end{array}$ & \multicolumn{3}{|c|}{$\begin{array}{c}\text { SIsbr } 2.0 \text { - Plataforma de Apolo à Declsăo } \\
\text { APN - Anállse de Produtlvidade do Negóclo } \\
\text { Relatórlo de Indlcadores }\end{array}$} & $\begin{array}{l}\text { Data Emissão: } \\
23 / 11 / 2018 \\
\text { Hora Emissão : } \\
08: 32: 11\end{array}$ \\
\hline $\begin{array}{ll}\text { Data de Referência: } 09 / 2018 & \text { Tipo: } \\
\text { Instituição: } 3164-\text { SICOOBSSICA UNIÃO }\end{array}$ & \multicolumn{4}{|c|}{$\begin{array}{ll}\text { Data/Hora Processamento (Cooperativa): } & \text { 01/11/2018 00:04:46 } \\
\text { Data/Hora Processamento (Sicoob): } & 16 / 11 / 2018 \text { 22:00:14 }\end{array}$} \\
\hline $\begin{array}{c}\text { COOPERATIVAS ANALISADAS } \\
\text { INDICES }\end{array}$ & $\begin{array}{c}\text { Cooperativa } \\
1\end{array}$ & $\begin{array}{l}\text { Consolidado da Central } \\
\qquad 79\end{array}$ & $\begin{array}{l}\text { Consolidado por Tipo } \\
\qquad 360\end{array}$ & $\begin{array}{l}\text { Consolidado Sicoob } \\
374\end{array}$ \\
\hline \multicolumn{5}{|l|}{ INDICADORES LEGAIS } \\
\hline Património de Referéncia - PR & $39.039 .892,57$ & & & \\
\hline Índice de Basiléia - IB (10,5\% RPC e 13\% RPS) & 20,06 & & & \\
\hline Índice / Grau de Imobilizaçāo - GI (50\%) & 21,01 & & & \\
\hline Razāo de Alavancagem (3\%) & 13,40 & & & \\
\hline \multicolumn{5}{|l|}{ LIQUIDEZ } \\
\hline Liquidez Geral & 112,64 & 117,80 & 120,82 & 121,06 \\
\hline Índice de Centralizaçāo Financeira - ICFs & 39,72 & & & \\
\hline Índice de Liquidez - IL & 16,04 & & & \\
\hline Liquidez Corrente & 1,13 & 1,18 & 1,21 & 1,21 \\
\hline Limite Global Atual & $148.736 .534,17$ & & & \\
\hline Limite Global Mess Realizado & $136.745 .836,77$ & & & \\
\hline Limite Global Mes Seguinte & $152.772 .593,95$ & & & \\
\hline Concentraçāo de Depósitos - 20 Maiores Depositantes & 13,29 & & & \\
\hline \multicolumn{5}{|l|}{ ESTRUTURA DE CAPITAL } \\
\hline Endividamento & 516,12 & 409,12 & 380,30 & 381,07 \\
\hline RENTABILIDADE & & & & \\
\hline Rentabilidade do Ativo & 3,47 & 3,17 & 3,12 & 2,95 \\
\hline Rentabilidade do PL & 20,72 & 15,49 & 14,67 & 13,84 \\
\hline Rentabilidade do PL (-JCP) & 23,18 & 16,93 & 17,76 & 17,07 \\
\hline INDICADORES DE CRÉDITO & & & & \\
\hline Concentraçāo de Risco - 20 Maiores Devedores & 20,51 & & & \\
\hline İndice Alavancagem (1) & 4,52 & & & \\
\hline Índice de Provisionamento-IPROV & 4,08 & 5,12 & $\mathbf{5 , 7 4}$ & 5,58 \\
\hline INAD 15 & 2,61 & 4,09 & 6,27 & 5,89 \\
\hline INAD 90 & 1,11 & 1,7 & 3,00 & 2,85 \\
\hline Índice de Prejulzo (IHH) & 5,89 & 7,54 & 9,87 & 9,71 \\
\hline Índice de Cobertura (índice de prov/Inad 90) & 3,70 & 2,89 & 1,91 & 1,95 \\
\hline CHEQUES DEVOLVIDOS & & & & \\
\hline Cheques Sustados & 0,29 & 0,35 & 0,39 & 0,37 \\
\hline Cheques Devolvidos & 2,13 & 3,27 & 2,74 & 2,55 \\
\hline Cheques Devolvidos/Contas Encerradas & 0,46 & 0,95 & 0,86 & 0,80 \\
\hline PRODUTIVIDADE & & & & \\
\hline Índice de Eficiência Padrāo - IEP & 56,56 & 58,65 & 54,03 & 52,99 \\
\hline Índice de Eficiência Ajustado Pelo Risco - IEA & 66,89 & 65,66 & 63,13 & 61,87 \\
\hline Índice de Cobertura Pessoal & 103,78 & 95,64 & 94,51 & 89,04 \\
\hline Índice de Cobertura Administrativa & 59,27 & 51,15 & 49,27 & 46,83 \\
\hline Ativo / Associados & $17.263,28$ & $19.133,38$ & $19.747,37$ & 22.304 .52 \\
\hline Depositos / Associados & $11.736,61$ & $11.793,19$ & $13.036,32$ & 14.63025 \\
\hline Operaçäes de Crédito / Associados & $11.077,65$ & $8.854,23$ & $9.74,95$ & $10.845,85$ \\
\hline Rendas de Serviços / Associados & 181,23 & 144,19 & 134,97 & 134,15 \\
\hline DADOS QUANTITATIVOS & & & & \\
\hline Número de Associados & 15.285 & 738.279 & 3.717 .725 & 3.960 .007 \\
\hline Associados Ativos & 11.874 & 540.515 & 2.578 .306 & 2.738 .824 \\
\hline Quantidade de Novos Associados no Més & 191 & 6.470 & 46.445 & 49.554 \\
\hline Quantidado do Associados Dosligados no MAs & 59 & 1.505 & 11216 & 11.751 \\
\hline Quantidade de Contas Correntes & 13.119 & 617.005 & 3.200 .855 & 3.392 .903 \\
\hline Quantidade de Novas Contas Correntes no Mes & 184 & 6.433 & 44.331 & 47.198 \\
\hline Quantidade de Contas Correntes Encerradas no MEs & 90 & 2.977 & 15.938 & 16.329 \\
\hline $\begin{array}{l}\text { ANÁLISE COMPARATIVA* } \\
\end{array}$ & Cooperativa & Consolidado da Central & Consolidado por Tipo & Consolidado Sicoob \\
\hline ATIVO TOTAL & 263.869 .278 & 178.807 .206 & 203.931 .390 & 236.165 .952 \\
\hline Operaçāes de Crédito & 169.321 .899 & 82.745.467 & 100.946 .003 & 114.838 .646 \\
\hline Pemanente & 14.882 .709 & 9.542 .584 & 8.843 .866 & 9.686 .669 \\
\hline DEPÓSITOS TOTAIS & 179.394 .069 & 110.210 .931 & 134.626 .307 & 154.908 .769 \\
\hline Depositos à vista & 55.672 .130 & 33.384 .474 & 32.402 .132 & 35.029 .289 \\
\hline Depbsitos à Prazo & 123.721 .938 & 76.826 .458 & 102.224 .175 & 119.879 .480 \\
\hline RECEITAS OPERACIONAIS & 9.783 .047 & 5.427 .117 & 6.676 .163 & 7.412 .463 \\
\hline PATRIMÔNIO LIQQUIDO (PL) & 42.827 .807 & 35.120 .779 & 42.459 .025 & 49.091 .674 \\
\hline Capital Social & 15.564 .466 & 18.370 .324 & 26.737 .302 & 30.851 .985 \\
\hline Sobras/Perdas do Exerclcio Atual & 7.093 .306 & 4.282 .030 & 5.091 .188 & 5.654 .099 \\
\hline Sobras/Perdas do Exerclcio Anterior & 0 & (841) & $(437.819)$ & $(421.431)$ \\
\hline TAXASDO SICOOB & Cooperativa & Consolidado da Central & Consolidado por Tipo & Consolidado Sicoob \\
\hline EMPRÉSTIMOS TOTAIS & 1,93 & 2,08 & 1,94 & 1,90 \\
\hline Cheque Especial & 6,21 & 5,30 & 5,45 & 5,19 \\
\hline Conta Garantida & 4,80 & 3,00 & 3,99 & 3,84 \\
\hline Empréstimos & 1,69 & 1,82 & 1,73 & 1,69 \\
\hline Financiamentos & 1,60 & 1,73 & 1,60 & 1,59 \\
\hline Operaçōes Renegociadas & 1,51 & 1,92 & 1,58 & 1,56 \\
\hline TITULOS DESCONTADOS & 1,95 & 2,08 & 2,16 & 2,16 \\
\hline FINANCIAMENTOS RURAIS TOTAIS & 0,76 & 0,81 & 0,73 & 0,74 \\
\hline Financiamentos Rurais Livres & 1,27 & 1,26 & 1,18 & 1,13 \\
\hline Financiamentos Rurais Direcionados & 0,54 & 0,64 & 0,59 & 0,63 \\
\hline Financiamentos Rurais Fontes Públicas & 0,00 & 0,66 & 0,67 & 0,67 \\
\hline DEPÓSITOS & 0,40 & 0,46 & 0,43 & 0,44 \\
\hline DEPÓSITOS À PRAZO & 0,44 & 0,45 & 0,45 & 0,45 \\
\hline SPREAD GLOBAL & 0,94 & 0,69 & 0,77 & 0,73 \\
\hline
\end{tabular}

Fonte: SICOOB União 09/2018 
A Seguir serão analisados e discutidos os dados apresentados no SIG setembro 2018, indicadores e gráficos referente ao mês base 09/2018 e realizar comparações com o mês base 10/2017.

\subsection{ANÁLISE DOS DADOS CONTÁBEIS E DISCUSSÕES DOS RESULTADOS}

Com base nos relatórios mensais emitidos pelos dados contábeis e sistemas de Informações gerenciais é possível realizar análises sobre a situação financeira da cooperativa, no qual serão apresentados a seguir, os resultados mensais - período 01/09/2018 a 30/09/2018. George e Jones (2008) afirma que:

O resultado do processo de controle é a capacidade de medir o desempenho com exatidão e regular a eficiência e a efetividade organizacional. Para exercer controle, os gerentes devem decidir quais objetivos irão medir - talvez objetivos pertinentes à produtividade, qualidade ou capacidade de responder aos clientes e então projetar sistemas de informação e de controle que irão fornecer os dados que precisam para avaliar o desempenho. A função de controlar também permite aos gerentes avaliar como eles estão desempenhando as outras três funções gerenciais planejar, organizar, liderar - e tomar uma ação corretiva.

Tal afirmativa é possível ser constatada nas análises a seguir, conforme figura 3 e 4:

Figura 3 Análise do Resultado mensal- 01/09/208 a 30/09/2018

SICOOB CENTRAL CREDIMINAS - GESEC - Centralização da Contabilidade

\begin{tabular}{|c|c|c|c|c|}
\hline Cooperativa de & $\begin{array}{c}\text { ga e Matipó Ltc } \\
8 \text { a 30/09/2018 } \\
\text { ago/2018 }\end{array}$ & B UNIÄO & & \\
\hline \multicolumn{5}{|l|}{ CONTAS PATRIMONIAIS } \\
\hline ORIGEM DE RECURSOS & 258.611 .367 & 263.869 .278 合 & 5.257 .911 & $2 \%$ \\
\hline DEPÓSITOS & 179.592 .054 & 179.394.069 & (197.986) & $0 \%$ \\
\hline REPASSES E EMPRÉSTIMOS & 29.821 .861 & 32.576 .062 䓟 & 2.754 .200 & $9 \%$ \\
\hline OUTRAS OBRIGAÇŌES & 7.342 .913 & 9.071 .340 藏 & 1.728 .427 & $24 \%$ \\
\hline PATRIMÓNIO LÍQUIDO & 41.854 .539 & 42.827 .807 숨 & 973.269 & $2 \%$ \\
\hline APLICAÇÃO DE RECURSOS & 258.611.367 & 263.869.278 & 5.257.911 & $2 \%$ \\
\hline TESOURARIA & 75.914.698 & 76.840 .250 个 & 925.552 & $1 \%$ \\
\hline OPERAÇŌES DE CRÉDITO & 165.038 .190 & 169.321 .899 苗 & 4.283 .709 & $3 \%$ \\
\hline OUTROS CRÉDITOS & 2.573 .376 & 2.538 .346 & $(35.029)$ & $-1 \%$ \\
\hline BENS NÃO DE USO PRÓPRIO & 286.075 & $286.075 \Rightarrow$ & 0 & $0 \%$ \\
\hline PERMANENTE & 14.799 .029 & 14.882 .709 会 & 83.679 & $1 \%$ \\
\hline \multicolumn{5}{|l|}{ CONTAS DE RESULTADO } \\
\hline DESPESAS COM CAPTAÇÃO DE DEPÓSITOS (B) & (638.087) & $(536.423)$ & 101.663 & $-16 \%$ \\
\hline \multicolumn{5}{|c|}{ 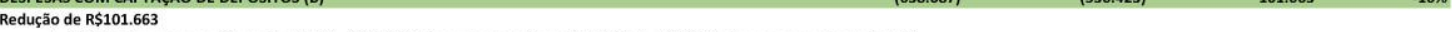 } \\
\hline \multicolumn{5}{|c|}{ 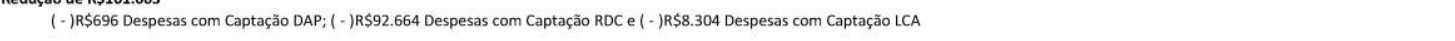 } \\
\hline DESPESAS COM REPASSES E EMPRÉSTIMOS (B) & (162.407) & (170.115) & (7.708) & $5 \%$ \\
\hline \multirow{2}{*}{\multicolumn{5}{|c|}{$\begin{array}{l}\text { Aumento de R\$7.708 } \\
\qquad(+) \text { R } \$ 7.708 \text { Despesas com Repasses Bancoob/Outros }\end{array}$}} \\
\hline & & & & \\
\hline RECEITA LÍQUIDA COM TESOURARIA (A) & 306.046 & 231.232 & (74.814) & $-24 \%$ \\
\hline \multirow{2}{*}{\multicolumn{5}{|c|}{$\begin{array}{l}\text { Redução de R\$74.814 } \\
\qquad+ \text { +R\$11.724 Despesas com Caixa e (-)R\$62.875 Receitas C }\end{array}$}} \\
\hline & & & & \\
\hline RECEITAS COM OPERAÇ̄̄ES DE CRÉDITO (A) & 2.926.101 & 2.831.397 & (94.704) & $-3 \%$ \\
\hline \multicolumn{5}{|c|}{ Redução de R\$94.704 } \\
\hline \multicolumn{5}{|c|}{ 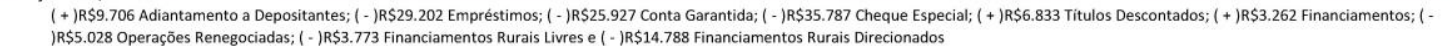 } \\
\hline MARGEM FINANCEIRA (B) + (A) & 2.431 .653 & 2.356 .090 & (75.563) & $-3 \%$ \\
\hline \multicolumn{5}{|l|}{ Redução de R\$75.563 (n) } \\
\hline (+ / -) PROVISÃO/REVERSÃ̃ DE CL/GARANTIAS PRESTADAS & (524.977) & 122.945 & 647.922 & $-123 \%$ \\
\hline 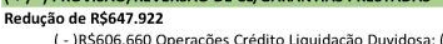 & & & & \\
\hline
\end{tabular}

Fonte: SICOOB União - GESEC Contabilidade centralizada 
Figura 4 Análise do Resultado mensal- 01/09/208 a 30/09/2018

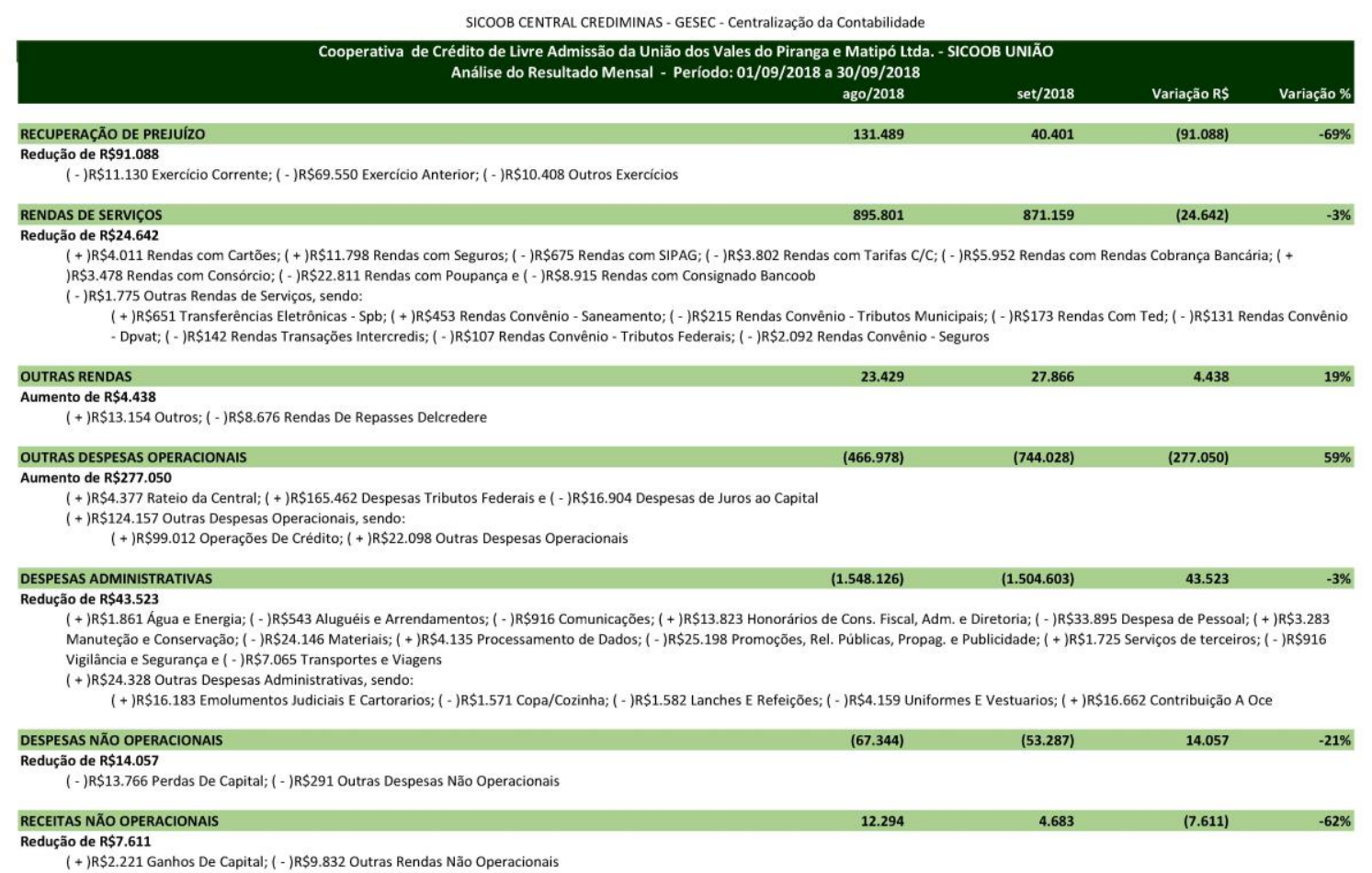

Fonte: SICOOB União - GESEC Contabilidade Centralizada

As análises acima são enviadas mensalmente pela Centralização da Contabilidade do SICOOB Central Crediminas, para a Administração do SICOOB União, no qual são apresentados os números, tendo como uma das principais finalidades apoio a gestão em seus planejamentos, controles e tomadas de decisões com base na situação financeira no qual a instituição se encontra.

Os relatórios, análises e demais informações apresentadas afirmam que a Cooperativa está em ótima situação, de acordo com o relatório de indicadores, apresentou como resultado final no mês de setembro de 2018 o valor de $\mathrm{R} \$ 1.121 .227,00$, acumulado no semestre de $\mathrm{R} \$ 3.481 .017,00$, resultado acumulado no exercício de $\mathrm{R} \$ 7.093 .306,00$. Possui 15.285 associados.

A cooperativa possui em seu quadro com base em setembro de 2018, 190 funcionários, sendo este número elevado no mês de novembro de 2018 para 195 funcionários, sendo em sua maioria com grau de escolaridade especialização em Pós-graduações. O quadro é composto por $73 \%$ funcionários do sexo Feminino e 27\% do sexo masculino. Apresenta um total de 72 certificações ANBIMA - CPA.

Os 6 gráficos a seguir, conforme figura 5, elaborados pela Contabilidade Centralizada - GESEC, apresentam dados analisados mês base 09/2018. 
Figura 5 - Gráficos competência 09/2018
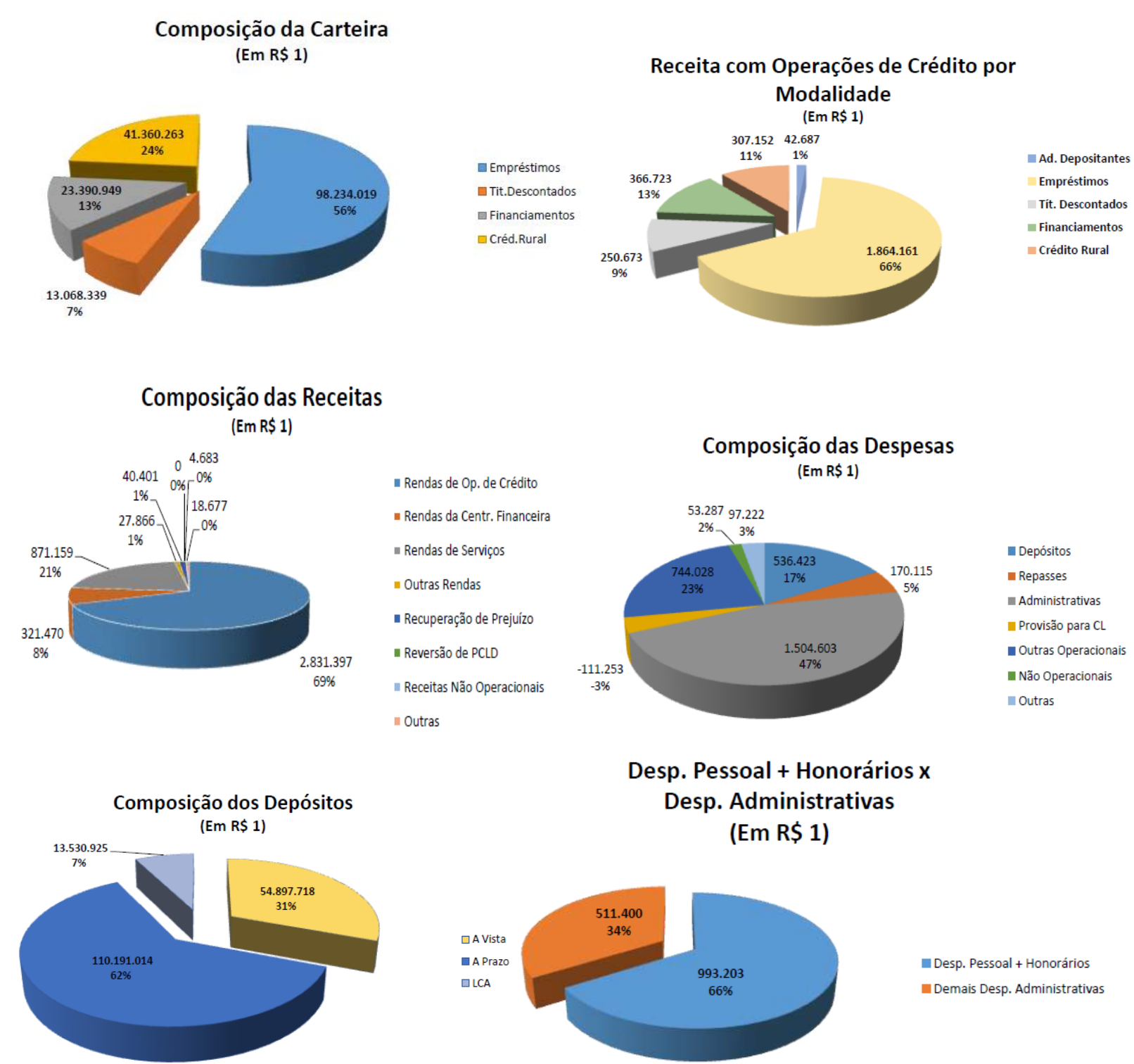

\section{Desp. Pessoal + Honorários $\mathbf{x}$ Desp. Administrativas} (Em R\$ 1)

Fonte: Sicoob União - GESEC- Contabilidade Centralizada

Receitas com prestação de serviços foi de $68 \%$ no valor de $\mathrm{R} \$ 591.484,00$ em atos cooperativos e $32 \%$ no valor de $\mathrm{R} \$ 279.675,00$ em atos não cooperativos, totalizando receitas com prestação de serviços em $\mathrm{R} \$ 871.159,00$, quase sendo possível a quitação das despesas Pessoal + Honorários que foi de $\mathrm{R} \$ 993.203,00$. O patrimônio líquido de $\mathrm{R} \$ 39.346 .791,00$ sendo $73 \%$ e Imobilizado de $\mathrm{R} \$ 14.882 .709,00$ sendo $27 \%$.

A composição do patrimônio apresentou em setembro de 2018, 51\% de Reserva legal; 40\% de capital social e $9 \%$ de sobras/perdas acumuladas. A seguir números comparativos referente a competência $10 / 2017$ e 09/2018. 
Vico Mañas (2012), aponta que "os resultados possibilitam a comparação entre resultados e padrões e conduzem à ação corretiva, por exemplo, dos próprios padrões de controle, da tomada de decisão e até de uma mudança nos requisitos de uma informação".

Quadro 1 - Dados Comparativos 10/2017 e 09/2018

\begin{tabular}{|c|c|c|c|}
\hline \multicolumn{5}{|c|}{ DADOS COMPARATIVOS 10/2017 e 09/2018 } \\
\hline Contas analisadas & out/17 & set/18 & Variação anual (\%) \\
\hline Saldo centralização Financeira & $85.679 .481,00$ & $70.246 .263,00$ & $\mathbf{- 1 8 , 0 1}$ \\
\hline Receita centralização Financeira & $561.235,00$ & $321.470,00$ & $\mathbf{- 4 2 , 7 2}$ \\
\hline Operações de Crédito & $103.038 .211,00$ & $169.321 .899,00$ & $\mathbf{6 4 , 3 3}$ \\
\hline Receitas de Operações de Crédito & $2.228 .290,00$ & $2.831 .397,00$ & $\mathbf{2 7 , 0 7}$ \\
\hline Saldo de deposito & $140.038 .592,00$ & $165.088 .732,00$ & $\mathbf{1 7 , 8 9}$ \\
\hline Despesa com captação + FGCoop & $695.682,00$ & $558.760,00$ & $\mathbf{- 1 9 , 6 8}$ \\
\hline Resultado Mensal & $706.688,00$ & $1.121 .227,00$ & $\mathbf{5 8 , 6 6}$ \\
\hline
\end{tabular}

Fonte Sicoob União 10/2017/09/2018

Com base no quadro 1 , nota-se que a cooperativa reduziu seus investimentos na centralização financeira, aumentando as operações de credito, o que gerou uma receita maior, o que contribui para aumentar o resultado mensal em setembro de 2018, que em destaque, foi elevado em 58,66\% se comparado com outubro de 2017.

Com base nos números contábeis apresentados através dos demonstrativos financeiros emitidos pelos sistemas de informações gerenciais utilizados pela cooperativa, é possível concluir que o SICOOB União apresenta uma excelente situação financeira, confirmando que a gestão da cooperativa está eficiente e eficaz.

\section{CONCLUSÃO}

A contabilidade é a ciência responsável pelo estudo dos fenômenos ocorridos no patrimônio das empresas, sendo responsável pelo registro, classificação e demonstração dos fatos ocorridos no patrimônio, através da escrituração contábil. O estudo foi realizado em uma Cooperativa de Crédito denominada SICOOB União. Sendo assim, para a definição do problema de pesquisa levou-se em consideração a expectativa de investigar a importância da Contabilidade nos processos de gestão das cooperativas de crédito.

Os objetivos específicos foram alcançados, sendo descritos conceitos sobre a contabilidade e seus tipos, Sistemas de informações gerenciais e cooperativismo com foco no ramo crédito, com apresentação de analises dos dados contábeis e discussão dos resultados apresentados nos relatórios emitidos pelos Sistemas de Informações gerenciais, indicadores e gráficos utilizadas pelo SICOOB União, mês base setembro de 2018 no qual foram comparadas as evoluções dos números financeiros da 
cooperativa com base nos 10/2017 e 09/2018; e por fim, foi avaliada a situação financeira do SICOOB União com base nos números apresentados, sendo possível concluir que o SICOOB União apresenta uma excelente situação financeira, confirmando que a gestão da cooperativa está eficiente e eficaz.

O alcance dos objetivos específicos foi favorável ao atendimento do objetivo geral, no qual foram apresentadas as contribuições da contabilidade nos processos de gestão das cooperativas de crédito, respondendo a a questão problema que foi descobrir como a contabilidade contribui nos processos de gestão das cooperativas de crédito.

Diante dos resultados apontados e por tratar-se de um estudo constituído de apenas pesquisa descritiva documental e bibliográfica, pôde-se perceber que o artigo traz como limitação, a impossibilidade do levantamento da totalidade das pesquisas realizadas com relação ao tema principal que a utilização da contabilidade nos processos de gestão das cooperativas. Neste sentido, sugere-se a realização de novas pesquisas, desta vez de forma quantitativa ou qualitativa, por meio de questionários ou entrevista, com vistas a ampliar as análises dos resultados desta pesquisa em Cooperativas de Crédito e demais Instituições financeiras, para ampliar as análises observadas neste estudo que apresentou a importância da Contabilidade nos processos de gestão das cooperativas de crédito.

\section{REFERENCIAS}

ATKINSON, Anthony A.; et al. Contabilidade Gerencial. Tradução: André Olímpio Mosselman Du Chenoy. 2a edição. São Paulo: Atlas, 2000.

BIALOSKORSKI NETO, Sigismundo. Gestão agroindustrial. GEPAI: Grupo de Estudos e Pesquisas Agroindustriais. São Paulo: Atlas, 1997.

CARVALHO, Deusvaldo. Orçamento e contabilidade pública: teoria, prática e mais de 800 exercícios. $5^{\text {a }}$ edição. Rio de Janeiro: Elsevier, 2010.

CORREIA, Ângela de Castro; MOURA, Kátia Regina Lima. A apreensão da cultura e o não compartilhamento dos valores cooperativistas em uma cooperativa sediada em Natal/RN. Caderno de Pesquisas de Administração, São Paulo, v. 8, n. 04, p. 5. out/dez. 2001.

CONSELHO FEDERAL DE CONTABILIDADE. RESOLUÇ̃̃ $\boldsymbol{O}$ - CFC $\boldsymbol{N}^{\boldsymbol{o}} 1.128 \mathrm{DE}$ 21.11.2008 - NBC $T 16.1$ - Conceituação, Objeto $e$ Campo de Aplicação. Disponível em: <http://www.normaslegais.com.br/legislacao/resolucaocfc1128_2008.htm>. Acesso em: 26 jul. 2015.

CREPALDI, Silvio Aparecido. Contabilidade Gerencial: Teoria e Prática. $3^{\text {a }}$ edição. São Paulo: Atlas, 2006.

ELDENBURG, Leslie G.; WOLCOTT, Susan K. Gestão de custos: como medir, monitorar e motivar o desempenho. Tradução: Luís Antônio Fajardo Pontes. Rio de Janeiro: LTC, 2007. 
FRANCO, Hilário. Contabilidade geral. 23a edição. São Paulo: Atlas, 1997.

JONES, Gareth R.; GEORGE, Jennifer M. Administração contemporânea. Tradução: Maria Lúcia G. L. Rosa. $4^{a}$ edição. São Paulo: McGraw-Hill, 2008.

LEITE, Jacqueline Rosadine de Freitas; SENRA, Ricardo Belízio de Faria. Aspectos Jurídicos das Cooperativas de Crédito. Belo Horizonte: Mandamentos, 2005.

MARQUES, Wagner Luiz. Contabilidade Gerencial à necessidade das Empresas. 2a edição. Paraná: Cidade, 2004.

NUNES, Paulo. Conceito de contabilidade. Disponível em: <http://www.notapositiva.com/ trab_professores/textos_apoio/contabilidade/01conccontabilidade.htm>. Acesso em: 25 nov. 2018.

OLIVEIRA, Luís Martins de; et al. Manual de contabilidade tributária. $5^{\text {a }}$ edição. São Paulo: Atlas, 2006.

ORGANIZAÇÃO E SINDICATO DAS COOPERATIVAS DE MINAS GERAIS. Informações econômicas e sociais do cooperativismo mineiro. Belo Horizonte: Gerência Técnica do Sistema Ocemg/Sescoop-MG. 2011.

PADOVEZE, Clovis Luis. Contabilidade Gerencial. Curitiba: IESDE, 2012.

RECH, Daniel. Cooperativas: uma alternativa de organização popular. Rio de Janeiro: DP\&A, 2000.

SANT'ANNA, Roberto de O. Contabilidade Gerencial. [Apostila digital]. Disponível em: <http://www.unisa.br/conteudos/6402/f1603556549/apostila/apostila.pdf>. Acesso em: 25 nov. 2018.

SANTOS, Boaventura de Sousa (Org.). Produzir para viver: os caminhos da produção não capitalista. Rio de Janeiro: Civilização Brasileira, 2002, p.11.

STAIR, Ralph M.; REYNOLDS, George W. Princípios de sistemas de informação. Tradução:

Harue Avritscher. $9^{a}$ edição. São Paulo: Cengage Learning, 2011.

STEFANO, S.R. ZAMPIER, M. A.; GRZESZCZESZYN, G. Cooperativas: características, gestão e relevância sócio-econômica para o Brasil. In: SEMINÁRIOS EM ADMINISTRAÇÃO - SEMEAD, 9, 2006, São Paulo. Anais... (São Paulo: [s.n.], 2006, 16p.

VERGARA, Sylvia Constant. Projeto e relatórios de pesquisa em administração. São Paulo: Atlas, 2005.

VICO MAÑAS, Antonio. Administração de sistemas de informação. $8^{\mathrm{a}}$ edição. São Paulo: Érica, 2012. 